15

\title{
Фотоэмиссионная ячейка матричного приемника вакуумного ультрафиолетового излучения
}

\author{
(C) Э.А Ильичев, А.Е. Кулешов, Р.М. Набиев, Г.Н. Петрухин, \\ Г.С. Рычков, Е.Г. Теверовская "
}

Национальный исследовательский университет „Московский институт электронной техники“, Москва

ฯ E-mail: mstlena2@mail.ru

\section{Поступило в Редакцию 6 декабря 2016 г.}

Рассматривается „слепая“ к солнечному излучению фотоэмиссионная ячейка матричного приемника вакуумного ультрафиолета для диапазона длин волн $50-225 \mathrm{~nm}$. Ячейка представляет в кремниевой пластине полость в форме усеченной пирамиды, стенки которой покрыты поликристаллической алмазной пленкой, играющей роль фоточувствительного катода. Конструкция ячейки позволяет организовать работу приемника „на прострел“, т. е. фотоны падают на одну сторону пластины, а фотоэлектроны выходят с другой ее стороны. Оценка фоточувствительности ячейки дает величину на уровне десятка фотонов.

DOI: 10.21883/PJTF.2017.07.44468.16596

Многоэлементные приемники вакуумного ультрафиолетового излучения (ВУФ) необходимы в астрофизике, медицине, микроэлектронике, биофизике и других областях науки и техники [1,2]. Первые матричные УФ-приемники разработаны на основе фотокатодов и микроканальных пластин (МКП) для спутников [3]. Их большим недостатком является чувствительность к солнечному излучению, к которому идеальные приемники ВУФ должны быть „слепыми“ (Solar blind). Алмазные детекторы привлекают внимание разработчиков электронной аппаратуры тем, что они как раз и обладают этим качеством. Основным препятствием широкого использования монокристаллических и поликристаллических алмазных пленок является их еще недостаточное качество из-за присутствия большого количества посторонней примеси и дефектов кристаллической решетки. Однако за последнее десятилетие фирмой „Element six“ достигнут значительный прогресс в разработке чистого, 
так называемого „электронного“, алмаза [4]. На основе естественного и искусственного алмаза разработан ряд дискретных твердотельных приемников ВУФ [5,6], имеющих высокий внешний квантовый выход EQE, доходящий до 100 при длине волны $200 \mathrm{~nm}$. Однако в твердотельных приемниках предельная чувствительность определяется также темновыми токами, которые в лучшем случае для дискретных приемников имеют величину не менее $10^{-12} \mathrm{~A} / \mathrm{cm}^{2}$. В твердотельных многоэлементных УФ-приемниках темновые токи намного больше, причем наблюдается их значительный разброс по элементам [7].

В данной работе предлагается новый подход в разработке приемников ВУФ. Он заключается в том, что пленочный алмазный фотокатод, используемый в режиме „на отражение“ и сформированный на поверхности кремниевой решетки, дает возможность приемнику работать в режиме „на прострел“. Конструктивно фотоприемник представляет кремниевую пластину, в которой сформированы однотипные фотоприемные ячейки. Каждая ячейка представляет усилитель-концентратор электронного потока (УКЭ), описанный в работе [8]. Ячейка представляет полость в форме усеченной пирамиды, стенки которой покрыты алмазной пленкой. В результате фотоприемник представляет кремниевую решетку, покрытую алмазной пленкой (КРАП), причем отверстия в решетке являются ячейками УКЭ. Замечательным свойством КРАП является то, что их можно использовать как аналоги МКП.

Один из вариантов фотоячейки представлен на рис. 1, $a$. Ячейка формируется селективным травлением, в результате чего она приобретает форму четырехгранной усеченной пирамиды, грани которой наклонены к основанию под углом $54.7^{\circ}$. Химическим парофазным осаждением (CVD-процесс) на стенки ячейки толщиной $\sim 3 \mu \mathrm{m}$ осаждается поликристаллическая алмазная пленка $p$-типа. Массив ячеек, образующих КРАП в форме круга, показан на рис. 1, $b$. Рис. 1, $c$ демонстрирует принцип работы ячейки, сформированной в пластине 1 , в режимах „на отражение“ („reflection“ mode - RM) и „на прострел“ („раss through“ mode - РТM). ВУФ (VUV), попадая в полость 2 и падая на алмазную пленку 3, рождает в ней фотоэлектроны, которые, выходя в вакуум, под действием электрического поля двигаются либо к сетке $\mathrm{G}$ (режим „на отражение“), либо через узкое отверстие к аноду A (режим „на прострел“). Режим „на отражение“ реализуется при $E_{A}=0 \mathrm{~V}$ и отрицательном напряжении $E_{F}$, а „на прострел“ - при положительном напряжении на аноде и $E_{F}=0 \mathrm{~V}$.

4 Письма в ЖТФ, 2017, том 43, вып. 7 

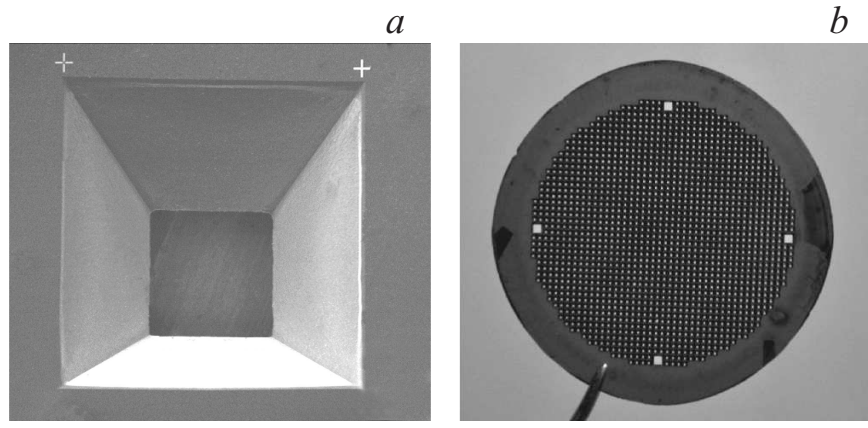

Distance $=1.02 \mathrm{~mm}$

$c$

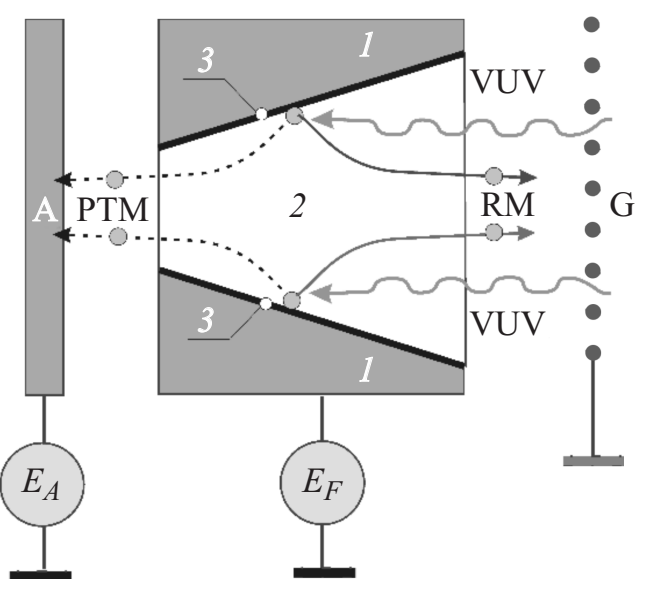

Рис. 1. Фотоэмиссионная ячейка: $a-$ электронный снимок ячейки; $b-$ кремниевая решетка, покрытая поликристаллической алмазной пленкой; $c-$ схема, поясняющая работу ячейки в режимах „на отражение“ и „на прострел“.

Для исследования фотоэмиссионных характеристик ячейки была изготовлена КРАП, содержащая $8 \times 8$ ячеек. КРАП имела размер $10 \times 10 \mathrm{~mm}^{2}$ при площади входного отверстия ячейки $\sim 1 \times 1 \mathrm{~mm}^{2}$ и выходного $-0.5 \times 0.5 \mathrm{~mm}^{2}$. Для получения ячеек меньшего размера, при используемой технологии их изготовления, следует брать пластины

Письма в ЖТФ, 2017, том 43, вып. 7 
меньшей толщины, переходя на кремниевые мембраны при микронных размерах ячеек.

Стенки ячеек покрыты поликристаллической алмазной пленкой, которая при толщине $3 \mu \mathrm{m}$ на поверхности имеет микрокристаллы размером $\sim 1 \mu \mathrm{m}$.

Исследуемая КРАП помещалась в вакуумную камеру, обеспечивающую давление $\sim 5 \cdot 10^{-7}$ Torr, и ВУФ, генерируемый лампой ДДС-30, проходя через сапфировое окно (Saphire Viewport - NW40 KF Flange), падал на КРАП. Поскольку лампа ДДС-30 излучает ультрафиолет с длиной волны не менее $185 \mathrm{~nm}$, а алмаз становится прозрачным для излучения с длиной волны более $225 \mathrm{~nm}$, то в ячейках фотоэлектроны будут рождаться фотонами только с длиной волны $185 \mathrm{~nm} \leqslant \lambda \leqslant 225 \mathrm{~nm}$. Важно отметить, что на эффективность ячейки оказывает влияние структура алмазной пленки. Так как алмазная пленка состоит из микрокристаллов, то в эмиссию фотоэлектронов будут вносить вклад только кристаллы, расположенные на поверхности пленки, так как фотоэлектроны из внутренних кристаллов, переходя границу раздела между кристаллами, будут либо рекомбинировать, либо захватываться поверхностными состояниями. Отсюда следует, что эффективная толщина алмазной пленки определяется размерами кристаллов на поверхности пленки. В нашем случае она равна $1 \mu \mathrm{m}$. В силу этого падающее излучение следует разделить на две составляющие: одна - это излучение, которое полностью поглощается в алмазе толщиной $1 \mu \mathrm{m}$, и другая - это излучение, которое только частично поглощается в слое толщиной $1 \mu \mathrm{m}$. Как следует из характера поглощения ультрафиолета алмазом [9], к первой части излучения следует отнести ВУФ с $185 \mathrm{~nm}<\lambda<205 \mathrm{~nm}$, ко второй $-205 \mathrm{~nm}<\lambda<225 \mathrm{~nm}$. Принимая во внимание характеристики излучения дейтериевой лампы ДДС-30, спектральную зависимость пропускания сапфирового окна, прохождение излучения через сетку $\mathrm{G}$, а также спектральную зависимость отражения и поглощения ультрафиолета для алмаза, получаем, что в диапазоне $185 \mathrm{~nm}<\lambda<205 \mathrm{~nm}$ мощность $P_{p h}$ ВУФ, генерирующего фотоэлектроны в исследуемой пленке, оказывается равной $\sim 0.37 \cdot 10^{-6} \mathrm{~W}$. Следовательно, в зоне проводимости алмаза рождается приблизительно $P_{p h} /(7 e)$ фотоэлектронов, где $e$ - заряд электрона. В работе [10] для алмазных пленок, используемых в УКЭ, показано, что вероятность электрону выйти в вакуум, когда он находится от границы алмаз - вакуум на расстоянии меньше диффузионной длины, равна $0.14-0.15$. Отсюда получается

$4^{*}$ Письма в ЖТФ, 2017, том 43, вып. 7 


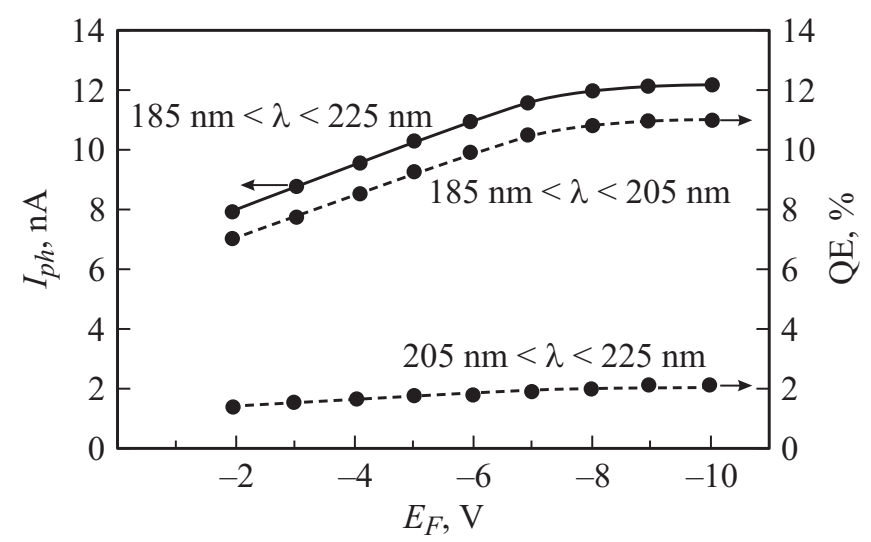

Рис. 2. Зависимости фототока $I_{p h}$ и квантовой эффективности QE от напряжения на ячейке $E_{F}$ в режиме „на отражение“.

максимальная величина фотоэмиссионного тока $I_{p h}=8 \mathrm{nA}$. Излучение с длиной волны 205-225 nm также частично поглощается поверхностными микрокристаллами, и оценка фототока для этого диапазона дает ток величиной $3.2 \mathrm{nA}$. Таким образом, следует ожидать, что общий ток будет иметь величину, близкую к $11.2 \mathrm{nA}$. Измерение фототока в режиме „на отражение“ реализуется при $E_{A}=0$ и $E_{F}<0$. Зависимость измеренного фототока от напряжения $E_{F}$ представлена на рис. 2 в виде сплошной линии. Видно, что фототок имеет величину, близкую к расчетной, что подтверждает правильность представления о процессе детектирования ВУФ. Оценки квантовой эффективности $(\mathrm{QE})$ алмазной пленки показывают, что для $185 \mathrm{~nm}<\lambda<205 \mathrm{~nm}$ она составляет $Q E \approx 11 \%$, а для диапазона $205<\lambda<225 \mathrm{~nm}-\mathrm{QE} \approx 2 \%$. Зависимости $\mathrm{QE}$ от $E_{F}$ представлены в виде пунктирных кривых на рис. 2 .

В работе [11] для диапазона $20-200 \mathrm{~nm}$ исследована квантовая эффективность алмазной пленки как фотокатода. Показано, что она возрастает при уменьшении длины волны и достигает $\sim 30 \%$ при $\lambda \sim 20 \mathrm{~nm}$, хотя при $\lambda \sim 200 \mathrm{~nm}$ она всего $\sim 2 \%$, т. е. значительно ниже, чем для пленки, используемой в предлагаемой ячейке. Рассмотренная выше квантовая эффективность получена в режиме „на отражение“. Оптимальная конструкция фотоприемника получается, когда фотокатод 


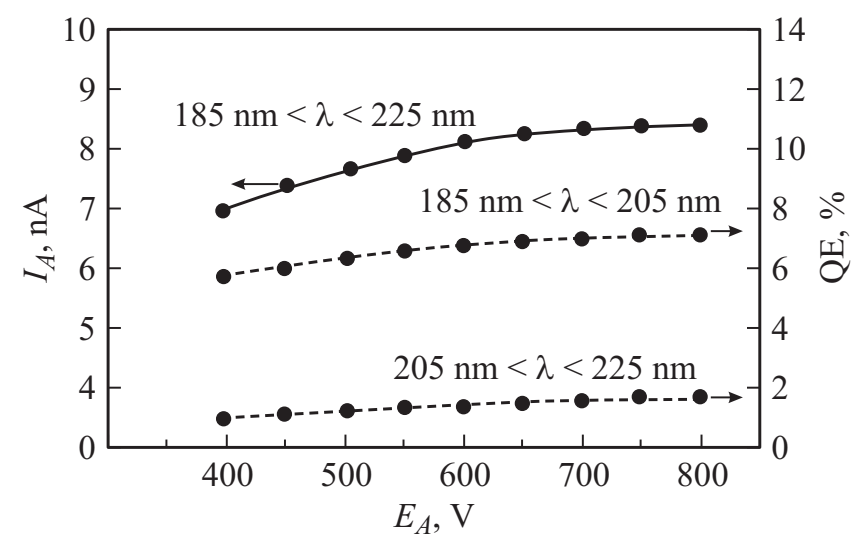

Рис. 3. Зависимости фототока $I_{A}$ и квантовой эффективности $Q E$ от напряжения на аноде $E_{A}$ в режиме „на прострел“.

работает в режиме „на прострел“. Этот режим реализуется при положительном напряжении на аноде $E_{A}>0$ и $E_{F}=0$ (рис. 1). На рис. 3 в виде сплошной кривой представлена зависимость фототока $I_{A}$ от напряжения на аноде $E_{A}$. Видно, что фототок в режиме „на прострел“меньше, чем фототок в режиме „на отражение“, хотя количество фотоэлектронов, образующих эти токи, одно и то же. Это связано с тем, что электрическое поле, определяющее траектории электронов в режиме „на прострел“, формируется через малое отверстие анодом, поэтому возникает конфигурация электрического поля, не реализующая выход всех фотоэлектронов к аноду. Тем не менее при достаточном напряжении на аноде доля рождаемых фотоэлектронов и достигающих анод составляет $\sim 0.85$. Учитывая соотношение фотоэлектронов для диапазонов $185 \mathrm{~nm}<\lambda<205 \mathrm{~nm}$ и $205 \mathrm{~nm}<\lambda<225 \mathrm{~nm}$, легко вычисляется квантовая эффективность для этих диапазонов в режиме „на прострел“. На рис. 3 зависимости QE от анодного напряжения $E_{A}$ представлены пунктирными кривыми. Видно, что QE уступает квантовой эффективности твердотельных приемников, особенно внешней квантовой эффективности $\mathrm{EQE}$, которая может достигать 100 [6]. Однако при больших значениях EQE быстродействие приемников низкое. Кроме того, как отмечалось выше, предельная чувствительность определяется

Письма в ЖТФ, 2017, том 43, вып. 7 
также темновыми токами, которые в матричных фотоприемниках не ниже $10^{-10} \mathrm{~A} / \mathrm{cm}^{2}$ [7]. В предлагаемой конструкции приемника темновой ток в основном определяется ионами остаточного газа и фотоэлектронами. При давлении электронно-оптических преобразователей $10^{-9}$ Torr концентрация остаточного газа составляет $\sim 3.7 \cdot 10^{7} \mathrm{~cm}^{-2}$. Вероятность ионизации электроном с энергией менее $1 \mathrm{keV}$ молекулы остаточного газа при этом давлении не превосходит 0.01 , т.е. при грубой оценке темновой ток будет меньше, чем фототок на два порядка. Детальный расчет предельной чувствительности показывает, что она может достигать величины не более десятка фотонов. В классической конструкции матричного ВУФ приемника, включающего фотокатод и МКП, фотокатод обладает значительно большей квантовой эффективностью, но он также чувствителен к солнечному ультрафиолету, вследствие чего его следует ослабить в $10^{6}-10^{8}$ раз, а это приводит к сопутствующему значительному ослаблению детектируемого ВУФ.

Чувствительность на уровне десятка фотонов предполагает значительное усиление сигнала, как в ФЭУ. Предлагаемая конструкция фотоприемника на основе КРАП позволяет просто реализовать такое усиление путем размещения одинаковых КРАП между приемной частью фотоприемника, которая конструктивно представляет такую же КРАП, и анодом. Тогда при соответствующих напряжениях на КРАП они будут играть роль аналогов МКП, причем исходный сигнал каждой ячейки будет усилен в $k^{N}$ раз, где $k$ - обеспечиваемое ячейками КРАП усиление, достигающее величины 30 и более [9], а $N$ - число КРАП.

Таким образом, предлагаемая фотоэмиссионная ячейка позволяет разработать высокочувствительный многоэлементный матричный приемник вакуумного ультрафиолетового излучения.

\section{Список литературы}

[1] Артюков И. // Фотоника. 2008. № 5. С. 26-33.

[2] Ulmer M.P. // Proc. SPIE. 2006. V. 6189. P. 61890-1.

[3] Johnson C.B. // Proc. SPIE. 1990. V. 1243. P. 2.

[4] www.e6cvd.com.

[5] Шаронов Г.В., Большаков А.П., Ральченко В.Г. и др. // Журнал прикладной спектроскопии. 2010. Т. 77. № 5. С. 714-719.

[6] Pace E., De Sio A. // Mem. S.A. It. Suppl. 2010. V. 14. P. 84-89.

Письма в ЖТФ, 2017, том 43, вып. 7 
[7] Алтухов А.А., Митягин А.Ю., Клочкова А.М., Орлова Г.А. // Технология и конструирование электронной аппаратуры. 2008. № 3. С. 1-6.

[8] Ilichev E.A., Kuleshov A.E., Poltoratskii E.A., Rychkov G.S. // Diamond Relat. Mater. 2011. V. 20. P. 23-25.

[9] Mildren Richard P., Rabeau James R. // Opt. Eng. Diamond. Wiley - VCH Verlog GmbH@Co.KGaA. 2013. P. 520.

[10] Dvorkin V.V., Dzbanovsky N.N., Suetin N.V., Rychkov G.S. et al. // Diamond Relat. Mater. 2003. V. 12. P. 2208-2218.

[11] Tremsin A.S., Siegmund O.H.W. // Diamond Relat. Mater. 2005. V. 14. P. 48-53.

Письма в ЖТФ, 2017, том 43, вып. 7 